\title{
5-HT serotonin receptors modulate mitogenic signaling and impact tumor cell viability
}

\author{
YESSENIA BALLOU $^{1 *}$, ALEXANDRIA RIVAS $^{1 *}$, ANDRES BELMONT $^{2}$, LUV PATEL $^{2}$, CLARISSA N. AMAYA $^{1}$, \\ SHANE LIPSON $^{2}$, THURAIEH KHAYOU ${ }^{1}$, ERIN B. DICKERSON ${ }^{3,4}$, ZEINA NAHLEH $^{2,5,6}$ and BRAD A. BRYAN ${ }^{1,2}$ \\ ${ }^{1}$ Department of Biomedical Sciences, ${ }^{2}$ Paul L. Foster School of Medicine, Texas Tech University Health Sciences Center, \\ El Paso, TX 79905; ${ }^{3}$ Department of Veterinary Clinical Sciences, University of Minnesota, Saint Paul, \\ MN 55108; ${ }^{4}$ Masonic Cancer Center, University of Minnesota, Minneapolis, MN 55455; ${ }^{5}$ Department \\ of Internal Medicine, Texas Tech University Health Sciences Center, El Paso, TX 79905; ${ }^{6}$ Department \\ of Hematology and Medical Oncology, Cleveland Clinic Florida, Weston, FL 33331, USA
}

Received January 15, 2018; Accepted July 13, 2018

DOI: $10.3892 /$ mco.2018.1681

\begin{abstract}
Symptoms of depression are present in over half of all cancer patients, and selective serotonin reuptake inhibitor (SSRI) anti-depressant medications are prescribed to nearly a quarter of these individuals in order to cope with their disease. Previous studies have provided evidence that elevated serotonin (5-HT) and serotonin receptor levels may contribute to oncogenic progression, yet little is known regarding the mechanism by which this occurs. The data demonstrated that serotonin receptor mRNAs and proteins are expressed across diverse cancer types, and that serotonin stimulation of tumor cells activates oncogenic signaling mediators including components of the AKT, CREB, GSK3, and MAPK pathways. Selective pharmacological inhibition of the seven known classes of 5-HT receptors in sarcoma and breast cancer cells resulted in dose dependent decreases in tumor cell viability, activation of the p53 DNA damage pathway, suppression of MAPK activity, and significantly reduced tumor volume in an in ovo model. Based on a retrospective clinical analysis of 419 patients diagnosed with breast cancer, we discovered that use of SSRIs was associated with a 2.3-fold increase in tumor proliferation rates for late stage patients based on their Ki-67 index $(\mathrm{P}=0.03)$. These data provide evidence that serotonin signaling pathways, which treating oncologists often pharmacologically target to assist cancer patients to psychologically cope with their illness, activate signaling pathways known to promote tumor growth and survival.
\end{abstract}

Correspondence to: Dr Brad A. Bryan, Department of Biomedical Sciences, Texas Tech University Health Sciences Center, 5001 El Paso Drive, El Paso, TX 79905, USA

E-mail: brad.bryan@ttuhsc.edu

*Contributed equally

Key words: cancer, neurohormone, serotonin, selective serotonin reuptake inhibitors, antidepressants, breast cancer, sarcoma

\section{Introduction}

Symptoms of depression are present in $\sim 55 \%$ of cancer patients, and selective serotonin reuptake inhibitor (SSRI) anti-depressant medications are prescribed in up to $20 \%$ of these individuals (1). SSRIs work by blocking reuptake of the biogenic monoamine serotonin [5-hydroxytryptamine (5-HT)], thus systemically elevating serotonin levels and leading to feelings of well-being and happiness. While serotonin is most noted as a neurotransmitter in the central nervous system, a local mediator in the gut, and a vasoactive agent in the blood, a connection between 5-HT receptor signaling and proliferation of diverse non-diseased cell types has been reported over the past two decades (2-5). Several studies have linked serotonin signaling to the promotion of tumor growth and metastasis in hepatocellular carcinoma, melanoma, as well as pancreatic, prostate, bladder, and breast cancer (6-19). Moreover, high levels of serotonin are capable of transforming non-tumorigenic cell lines such as NIH3T3 fibroblasts $(20,21)$, and serum levels of this neurotransmitter have been used as a prognostic marker for urothelial, prostate, and renal cell carcinoma (22).

Serotonin can exert multiple and sometimes opposing actions on its target cells. These effects are determined by the characteristics of the 5-HT receptor/s with which it interacts and the intracellular signaling pathways coupled to each receptor. In humans, there are seven 5-HT receptor families (six families of G-protein coupled receptors and one ion channel family) that are expressed in a tissue-specific manner across a variety of normal and tumor cells, and the levels of a handful of these receptors have been correlated with increased tumorigenicity. For instance, strong expression of 5-HT1A and B have been correlated with high Gleason grades, as well as lymph node and bone metastasis in prostate cancer (23). 5-HT2B expression has been linked to induction of tumor formation in nude mice (24), while 5-HT4 is overexpressed in high grade prostate tumors and has been shown to facilitate cell growth in an androgen depleted environment $(25,26)$.

Though some 5-HT receptors have been associated with oncogenic processes, a comprehensive analysis of 5-HT receptors across both carcinomas and sarcomas has not yet 
been performed. In this study, we examined the expression of 5-HT receptors across a large panel of cancers, and employed pharmacological inhibitors of each of the seven classes of 5-HT receptors to evaluate their effects on tumor cell viability and oncogenic signaling. We then performed a retrospective clinical analysis of a large cohort of breast cancer patients looking specifically at the correlation between SSRI use and tumor proliferation rates.

\section{Materials and methods}

Meta-analysis of genomic expression data. Meta-analysis was performed to examine the HTR mRNA expression levels on 1036 cancer cell lines housed in the Cancer Cell Line Encyclopedia (CCLE) (www.broadinstitute. org/ccle/home) (27). Normalized heatmap data was generated in Cluster 3.0 software (http://bonsai.hgc. jp/ mdehoon/software/cluster/software.htm) (using unsupervised hierarchical clustering analysis (uncentered correlation similarity metric, centroid linkage). Heatmaps were visualized using Java Treeview software (http://jtreeview.sourceforge. net/). Meta-analysis of 5-HT protein expression was performed using existing annotated databases from the Human Protein Atlas (HPA; www.protein atlas.org). Antigen staining was evaluated as positive or negative, and represented as a percentage of the total number of cancer tissues tested for each cancer type. Meta-analysis of HTR and TPH genes in normal mouse breast tissue $(\mathrm{N}=5)$, non-metastatic breast tumors from 67NR xenografts $(\mathrm{N}=5)$, and metastatic breast tumors from 4T1 xenografts $(\mathrm{N}=4)$ was performed on Affymetrix mouse Genome 430 2.0 Array data housed in Gene Expression Omnibus (GEO; cat. no. GSE62817).

Cell culture. Sarcoma and breast cancer cell lines were cultured in incubators maintained at $37^{\circ} \mathrm{C}$ in the presence of $5 \% \mathrm{CO}_{2}$. AU565 (cat. no. CRL-2351), HCC70 (cat. no. CRL-2115), and BT-549 (cat. no. HTB-122) human breast cancer lines, and SW872 human liposarcoma cells (cat. no. HTB-92) were grown in RPMI-1640 medium supplemented with $10 \%$ fetal bovine serum and penicillin/streptomycin antibiotics (all from ATCC, Manassas, VA, USA). The SK-BR-3 human breast cancer line (cat. no. HTB-30; ATCC) was grown in McCoy's medium supplemented with $10 \%$ fetal bovine serum and penicillin/streptomycin antibiotics. The A673 human Ewing's sarcoma cell line (cat. no. CRL-1598) and the HOS human osteosarcoma cell line (cat. no. CRL-1543) (both from ATCC) were grown in Dulbecco's modified eagle medium supplemented with $10 \%$ fetal bovine serum and penicillin/streptomycin. The COSB canine hemangiosarcoma cell line (28) was grown in EGM-2 basal medium with the EGM-2 Bullet kit (cat. no. CC-3162; Lonza, Basel, Switzerland). The epidemiology and cancer biology of the canine cell line has been shown to extrapolate directly to humans (28).

Immunoblotting. Cell lysates were collected as indicated for each experiment, subjected to SDS-PAGE, and transferred to polyvinylidene fluoride membranes using the Trans-Blot Turbo Transfer System (Bio-Rad, Hercules, CA, USA). Membranes were blocked in tris buffered saline plus 3\% bovine serum albumin and $0.05 \%$ Tween-20, and incubated with the following antibodies as indicated for each experiment: Ki-67 (cat. no. ab16667; 1:1,000 dilution, $1 \mathrm{~h}$ incubation at $25^{\circ} \mathrm{C}$; Abcam, Cambridge, UK), Kinome View Profiling kit (cat. no. 9812; 1:2,000 dilution for all antibodies, $1 \mathrm{~h}$ incubation at $25^{\circ} \mathrm{C}$; Cell Signaling Technology, Danvers, MA, USA) or anti-actin (cat. no. sc8432; 1:1,000 dilution, $1 \mathrm{~h}$ incubation at $25^{\circ} \mathrm{C}$; Santa Cruz Biotech, Dallas, TX, USA). Each primary antibody was detected with 1:1,000 HRP-conjugated secondary antibody [Santa Cruz Biotechnology cat. no. sc-2357 (anti-rabbit) or cat. no. sc-2005 (anti-mouse); 1:1,000 dilution, $1 \mathrm{~h}$ incubation at $25^{\circ} \mathrm{C}$ ], subjected to Supersignal West Dura Extended Duration Substrate (ThermoFisher Scientific, Waltham, MA, USA), and digitally captured using a GE Image Quant Las4000 imaging system.

Antibody arrays. The Phospho-Mitogen-activated protein kinase (MAPK) Antibody Array (cat. no. ARY002B; R\&D Systems, Minneapolis, MN, USA) was performed on HOS cells as indicated according to the manufacturer's instructions. Normalized heatmap data was generated in Cluster 3.0 software (http://bonsai.hgc.jp/ mdehoon/software/cluster/software.htm) (using unsupervised hierarchical clustering analysis (uncentered correlation similarity metric, centroid linkage). Heatmaps were visualized using Java Treeview software (http://jtreeview.sourceforge.net/).

Proliferation/viability assays. To measure the effects of serotonin or 5-HT pharmacological inhibitors on tumor cell viability, sarcoma and breast cancer cells were plated in 96-well plates at approximately $\sim 75 \%$ confluence, treated as indicated, and cell viability was measured after $24 \mathrm{~h}$ via fluorescent excitation at $530 \mathrm{~nm}$ with the Alamar Blue cell viability assay (ThermoFisher Scientific).

Tumor spheroid model. HOS cells were grown in hanging drops (3,000 cells/drop) for $48 \mathrm{~h}$ as previously described for other cell lines (29), and transferred to non-adherent well plates. Spheroids were treated as indicated for $48 \mathrm{~h}$ and photos were taking using bright field microscopy.

In ovo tumor assay. All chicken embyo experiments were performed prior to hatching, thus these experiments were considered exempt from ethics approval based on PHS policy. Chorioallantoic membrane (CAM) tumor assays were performed as previously described using rainbow hen eggs (Gallus gallus domesticus) (30). A false air-sac was generated directly over the CAM of fertilized chicken eggs (7 days post-fertilization). 20,000 dissociated CosB tumor cells were soaked onto a $5 \mathrm{~mm}^{2}$ gelatin sponge and then placed onto the CAM. A sham solution of isotonic saline solution $(\mathrm{N}=3)$ or 100 nM SB-269970 (N=3) was added daily directly onto the CAM tumor. After $72 \mathrm{~h}$ of treatment (13 days post-fertilization), the tumors were collected, weighed, and photographed on a lightbox.

Retrospective clinical analysis. Retrospective analysis of clinical data was carried out with the approval of the Texas Tech University Health Sciences Center Institutional Review Board. Analysis of 419 female patients diagnosed with invasive ductal carcinoma at the Texas Tech Breast Care Center between 
Table I. Demographic characteristics of retrospective study population.

\begin{tabular}{lrc}
\hline Demographic & Number & Percentage \\
\hline Caucasian, Hispanic & 378 & 90 \\
Caucasian, white & 4 & 1 \\
Native American & 5 & 1 \\
Other & 32 & 8 \\
\hline
\end{tabular}

the years of 2010 to 2014 was performed. The demographic characteristics of the study population are described in Table I. IHC for estrogen receptor (ER), progesterone receptor (PR), Her-2/neu, and Ki-67 tumor proliferative index were available for all patients. Breast cancer clinico-pathological features (age at diagnosis, tumor size, tumor grade, lymph node status, hormonal receptor status) were extracted from each case report. Patients were considered positive for SSRI usage if they had been prescribed SSRIs at any point in the year prior to or at the time of diagnosis. Of a total of 419 patients included in this study, we identified 28 patients taking SSRIs and 391 patients who were not taking SSRIs during the defined time frame.

Statistical analysis. All in vitro experiments were performed at least three independent times, with at least four technical replicates per assay. Unpaired t-tests or one-way analysis of variance (ANOVA) followed by Dunnett's multiple comparison post hoc test were used to determine the statistical significance for all in vitro experiments. Differences were considered statistically significant if the P-value was less than 0.05. The retrospective relationship between SSRI usage and the Ki-67-based proliferative index of the breast tumors was determined with the Mann-Whitney rank sum test. Comparisons of SSRI usage to tumor hormonal receptor status and tumor staging were calculated with the Fisher's exact test. Statistical analyses were carried out using Graphpad Prism. Differences were considered statistically significant if the P-value was $<0.05$.

\section{Results}

5-HT receptor expression across diverse cancers. To evaluate HTR gene (encoding 5-HT receptors) expression in human cancers, we performed meta-analysis on the global gene expression profiles obtained from microarray analysis housed in the Cancer Cell Line Encyclopedia (CCLE; https://portals. broadinstitute.org/ccle). This database contains quantitative data on over 1,000 different cell lines representing a diverse array of cancer types including carcinomas, sarcomas, and hematopoietic cancers. Unique expression patterns emerged for many of the HTR mRNAs (Fig. 1). Analysis of the CCLE data revealed clear clustering of gene over-expression dependent on tumor origin was observed for several HTR mRNAs including HTR3A (largely lung and hematopoietic/lymphoid tumor cell lines), HTR IF (largely hematopoietic/lymphoid, bone sarcoma, and soft tissue sarcoma cell lines), HTR ID (largely mixed digestive track cancer cell lines), HTR2A (largely central nervous system, breast, and bone sarcoma cell lines), and HTR $2 B$ (largely skin cancer cell lines). Though

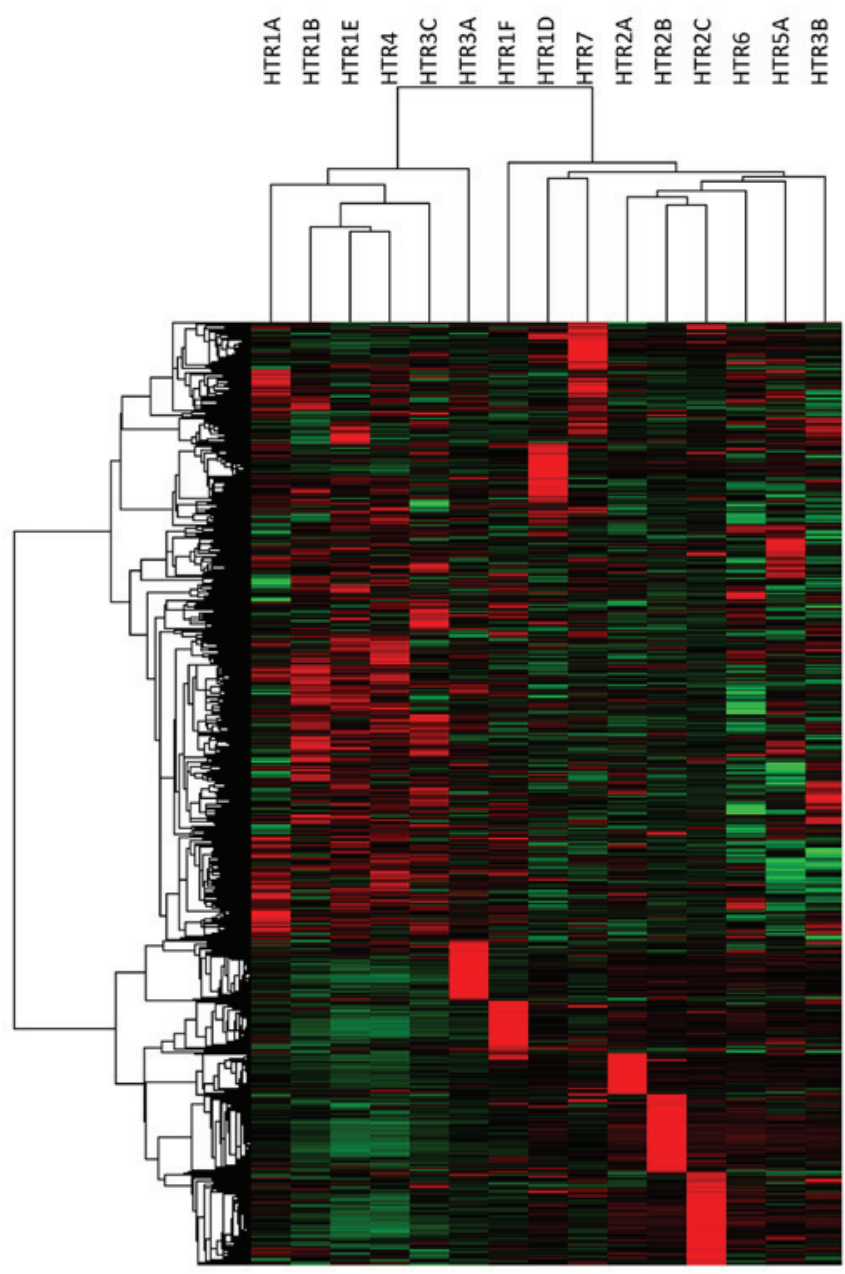

Figure 1. HTR mRNA expression across diverse cancer cell lines. Meta-analysis of HTR mRNA was performed across approximately 1,000 cancer cell lines housed in the Cancer Cell Line Encyclopedia (CCLE) (www.broadinstitute.org/ccle/home). Unsupervised hierarchical clustering of the mRNA expression patterns is depicted in a heatmap. Red, enhanced expression; green, reduced expression.

clustering of expression patterns were observed other $H T R$ mRNAs, the cell lines composing these clusters were varied among cancer origins. As mRNA expression is not always reflective of protein levels, we performed meta-analysis of tissue pathology data housed in the Human Protein Atlas to analyze 5-HT protein expression across cancers. This repository contains stained tissue samples representing the most common forms of cancer, totaling 216 different cancer samples on which immunohistochemistry data is reported for many proteins. Our meta-analysis of the pathology-based annotation of 5-HT1A, 1D, 1E, 1F, 2A, 2B, 3B, 4, 5A, and 7 protein expression levels is illustrated in Table II. A handful of the 5-HT receptors were not reported due to their absence from the Human Protein Atlas, therefore IHC analysis for these proteins is not included in our results. Our meta-analysis revealed, with the exception of 5-HT1A and 2A, that the majority of 5-HT receptors analyzed were expressed across many cancers.

Serotonin modulates intracellular signaling pathways. To determine if serotonin is capable of enhancing the proliferation of rate of cancer cells, we serum starved a panel of diverse tumor cell lines representing 4 breast cancers (AU565, 
Table II. Percentage of cancer tissues expressing 5-hydroxytryptamine (5-HT) receptors based on IHC staining.

\begin{tabular}{lrrrrrrrrrr}
\hline & 5-HT1A & 5-HT1D & 5-HT1E & 5-HT1F & 5-HT2A & 5-HT2B & 5-HT3B & 5-HT4 & 5-HT5A & 5-HT7 \\
\hline Breast & 0 & 100 & 100 & 67 & 9 & 92 & 55 & 91 & 100 & 100 \\
Cervical & 17 & 73 & 100 & 82 & 8 & 73 & 50 & 50 & 83 & 92 \\
Colorectal & 9 & 100 & 91 & 91 & 0 & 73 & 92 & 100 & 100 & 82 \\
Glioma & 13 & 100 & 100 & 18 & 0 & 0 & 55 & 36 & 9 & 0 \\
Head and neck & 0 & 100 & 75 & 75 & 50 & 50 & 75 & 25 & 75 & 0 \\
Liver & 17 & 100 & 73 & 55 & 10 & 20 & 67 & 75 & 45 & 73 \\
Lung & 0 & 100 & 100 & 45 & 8 & 67 & 82 & 54 & 67 & 100 \\
Lymphoma & 0 & 67 & 70 & 8 & 0 & 0 & 50 & 58 & 27 & 17 \\
Melanoma & 8 & 100 & 100 & 33 & 17 & 0 & 91 & 45 & 50 & 42 \\
Pancreatic & 0 & 100 & 100 & 67 & 10 & 80 & 83 & 100 & 80 & 58 \\
Prostate & 0 & 100 & 100 & 67 & 0 & 36 & 82 & 92 & 55 & 92 \\
Non-Mel skin & 0 & 100 & 100 & 90 & 18 & 8 & 67 & 36 & 58 & 36 \\
\hline
\end{tabular}

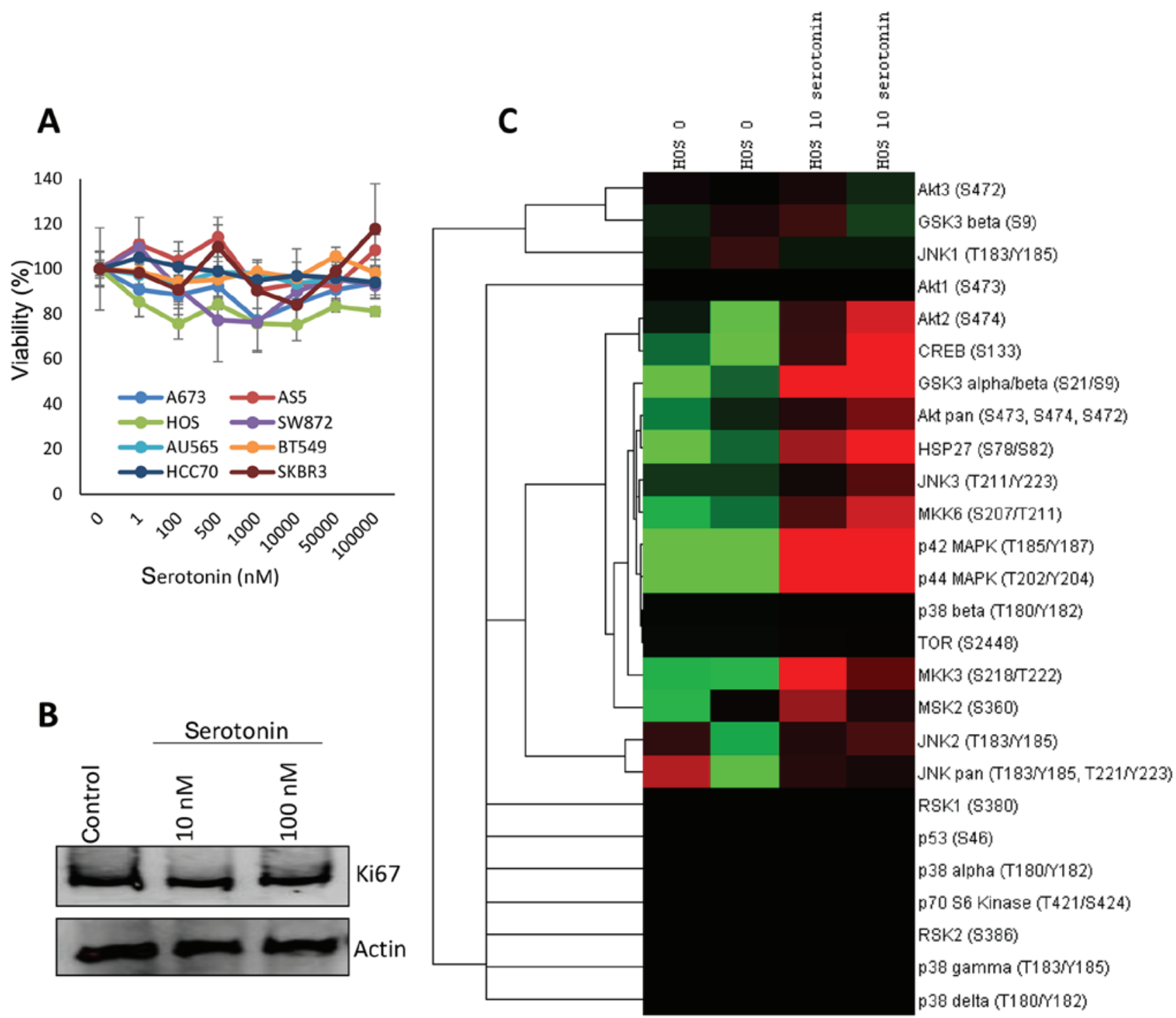

Figure 2. Serotonin modulates intracellular signaling pathways. (A) A panel of breast cancer, soft tissue sarcoma, and bone sarcoma cells were subjected to increasing serotonin concentrations $(1 \mathrm{nM}$ to $100 \mu \mathrm{M})$. Alamar blue viability assays were performed after $48 \mathrm{~h}$, and the data are presented as a line graph. (B) Immunoblotting analysis for the proliferation marker Ki-67 in HOS osteosarcoma cells treated with control, 10 or $100 \mathrm{nM}$ serotonin for $24 \mathrm{~h}$. $\beta$-actin was used as a loading control. (C) Antibody array of HOS osteosarcoma cell lysates collected after treatment for 10 min with $10 \mathrm{nM}$ serotonin or a sham control. Red, enhanced expression; green, reduced expression. Two technical replicates of each time point are displayed. 
BT549, HCC70, and SK-BR-3), 2 soft tissue sarcomas (CosB hemangiosarcoma cells and SW872 liposarcomas cells), and 2 bone cancer (A673 Ewing's sarcoma cells and HOS osteosarcoma cells) for $24 \mathrm{~h}$. We then treated each cell line with increasing concentrations of serotonin (1 to $\left.1 \times 10^{5} \mathrm{nM}\right)$, and cell viability was accessed after $48 \mathrm{~h}$. No major changes in the proliferation rate were observed for any of the cell lines following serotonin treatment relative to the untreated control (Fig. 2A). These data were confirmed in HOS osteosarcoma cells via immunoblotting by using the proliferative marker Ki-67 (Fig. 2B).

We next sought to determine if the presence of serotonin alters intracellular signaling of the cancer cell lines. To accomplish this, HOS osteosarcoma cells were serum starved overnight and stimulated with $10 \mathrm{nM}$ serotonin or a sham control for $10 \mathrm{~min}$. Lysates were collected and the phosphorylation status of 24 kinases implicated in mitogenic and survival processes were examined using antibody arrays. Serotonin stimulation resulted in a marked increase in the activation of Akt2, CREB, GSK3, HSP27, and multiple MAPK signaling mediators (Fig. 2C).

Selective 5-HT receptor blockade reduces cancer cell viability and tumor growth. Because serotonin modulated the levels of kinases involved in cancer cell signaling pathways, we determined whether inhibition of 5-HT receptor activity was capable of affecting cancer cell viability. We subjected the cell line panel consisting of 4 breast cancers (AU565, BT549, HCC70, and SK-BR-3), 2 soft tissue sarcomas (CosB hemangiosarcoma cells and SW872 liposarcomas cells), and 2 bone cancer (A673 Ewing's sarcoma cells and HOS osteosarcoma cells) to highly selective 5-HT receptor antagonists (Table III), and cell viability was assayed $24 \mathrm{~h}$ post-treatment. Dose-dependent reductions in cell viability were observed for most of the 5-HT receptor antagonists across the panel of cancer cell lines (Fig. 3A-G). Notable exceptions were pirenperone (5-HT2 antagonist) and dolasetron mesylate (5-HT3 antagonist), which did not reduce cell viability across any of the cancer cell lines. Moreover, A673, HOS, and SK-BR-3 tumor cells were relatively more resistant to 5-HT antagonism compared to the other cells lines, despite expression of selected HRT mRNAs in each of these cell lines (based on CCLE data). A representative image of the SW872 liposarcoma cell line treated for $24 \mathrm{~h}$ with SB-269970 (5-HT7 antagonist) is shown in Fig. 4A. We confirmed the efficacy of SB-269970 to abrogate cell viability in the HOS osteosarcoma cell line using a three-dimensional tumor spheroid model, whereby the 5-HT7 receptor antagonist reduced tumor cell viability in a dose dependent manner after $48 \mathrm{~h}$ (Fig. 4B). To expand our in vitro results into an in vivo xenograft tumor model, we subjected CosB hemangiosarcoma tumors grown on CAMs to daily treatments of the 5 -HT7 antagonist $\left(5 \times 10^{-9}\right.$ grams/day) or a control sham. Tumors treated with the 5-HT7 antagonist exhibited significantly smaller tumor sizes compared to the sham control (Fig. 4C and D).

Selective 5-HT7 receptor blockade modulates intracellular signaling in cancer cells. To detect the phosphorylation status of proliferation and survival regulators following 5-HT antagonism, we treated HOS osteosarcoma cells with the
Table III. 5-Hydroxytryptamine (5-HT) receptor antagonists used in this study.

\begin{tabular}{lc} 
Antagonist & Target receptor \\
\hline (S)-WAY 100135 & 5-HT1 \\
Pirenperone & 5-HT2 \\
Dolasetron mesylate & 5-HT3 \\
GR-113808 & 5-HT4 \\
SB-699551 & 5-HT5 \\
SB-271046 & 5-HT6 \\
SB-269970 & 5-HT7 \\
\hline
\end{tabular}

Table IV. Selective serotonin reuptake inhibitor (SSRI) usage identified in the retrospective study.

\begin{tabular}{lcl}
\hline SSRI & No. of patients & \multicolumn{1}{c}{ Dose range } \\
\hline Escitalopram & 4 & $10-20 \mathrm{mg}$ daily \\
Fluoxetine & 1 & $20 \mathrm{mg}$ daily \\
Paroxetine & 1 & $20 \mathrm{mg}$ daily \\
Sertraline & 21 & $25-100 \mathrm{mg}$ daily \\
Unknown & 1 & Unknown \\
\hline
\end{tabular}

5-HT7 receptor antagonist for three h, collected cell lysates, and performed antibody arrays to quantify changes in protein phosphorylation. Antagonist treatment resulted in a marked increase in p53 phosphorylation and reductions in the phosphorylation status of both p38 and p42 MAPK (Fig. 5A). To more broadly evaluate the panel of selective 5-HT receptor antagonists, we collected protein lysates from HOS cells treated for three h with each selective 5-HT antagonist (100 nM), and performed immunoblots using a set of phospho-motif antibodies that cover a large portion of the kinome regulated by diverse kinase families. Our data revealed, with the exception of 5-HT3 antagonists, treatment with many of the antagonists resulted in reductions in substrate phosphorylation for signaling pathways including CDK, MAPK, and AKT (Fig. 5B).

SSRI use is associated with increased tumor cell proliferation in late stage breast cancer patients. We carried out a retrospective clinical analysis of 419 patients diagnosed with breast cancer to assess the association between the use of SSRIs and breast tumor proliferation rates. Patients were stratified based on SSRI use. A description of the various SSRIs taken by these patients is exhibited in Table IV. The Ki-67-based proliferative index was determined from pathology samples taken at each patient's diagnostic biopsy. No difference was found in tumor staging or hormone receptor status between users of SSRIs and non-users; however, in patients with late stage breast cancer, use of SSRIs was significantly associated with increased tumor proliferative index (2.3-fold increase) compared to patients who were non-users of SSRIs $(\mathrm{P}=0.03)$ (Table V; Fig. 6A). To determine if expression changes in 5HT receptors or biosynthetic enzymes contribute to SSRI-dependent alterations in proliferation rates between 

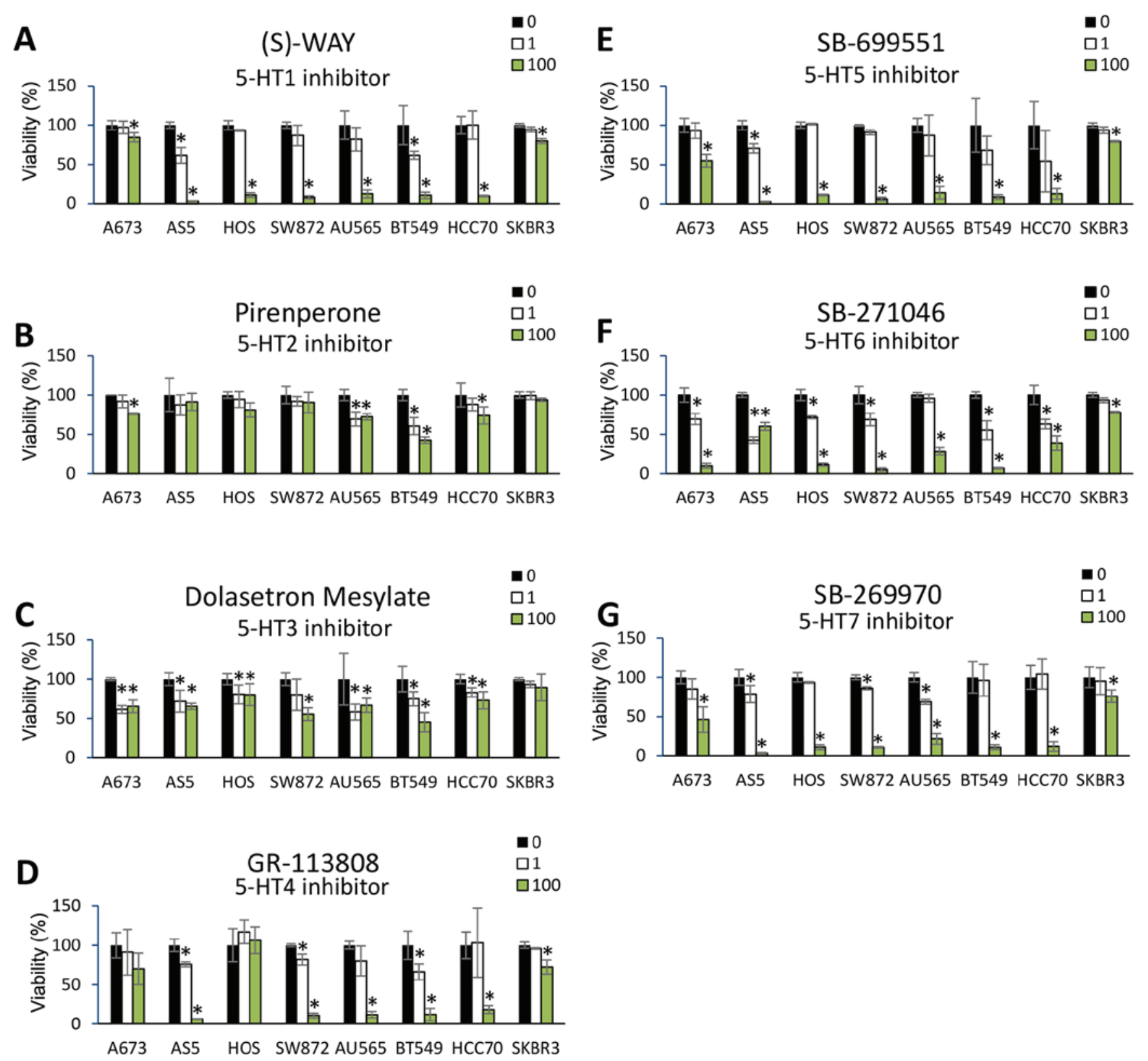

Figure 3. 5-Hydroxytryptamine (5-HT) antagonism inhibits cancer cell viability. (A-G) A panel of breast cancer, soft tissue sarcoma, and bone sarcoma cells were treated with 0,1 , or $100 \mathrm{nM}$ highly selective 5-HT antagonists as indicated. Alamar blue viability assays were performed after 48 h, and the data are presented as bar graphs. ${ }^{\mathrm{P}}<0.05$ vs. the control.

early and late stage breast cancer, meta-analysis of HTR and TPH genes was performed for normal mouse breast tissue, non-metastatic breast tumors from 67NR xenografts, and metastatic breast tumors from 4T1 xenografts based on data from the Gene Expression Omnibus (GEO cat. no. GSE62817). No statistical difference in expression patterns was observed for HTR or TPH mRNAs between normal, non-metastatic, and metastatic breast tissue (Fig. 6B).

\section{Discussion}

In this study, we demonstrated that several 5-HT receptors are expressed across a diverse array of cancers, and that serotonin signaling through the 5-HT receptors plays a role in the control of cancer cell viability through modulating key mitogenic signaling pathways. Furthermore, we revealed that use of SSRIs at the time of breast cancer diagnosis is correlated with increased tumor proliferative indices in late stages of the disease.

Expression of 5-HT receptors has been reported in hepatocellular carcinoma, leiomyosarcoma, and ovarian and breast cancer (6-8,17,31-34). Moreover, 5-HT1D, 5-HT2B and 5-HT7 receptors are overexpressed in hepatocellular carcinoma (7) and 5-HT1A and B are correlated with high Gleason grades and metastasis in prostate cancer $(23,25,26)$. Increases in serum serotonin itself have been shown to serve as a marker for early stage hepatocellular carcinoma development (35). In the current study, we took advantage of existing gene expression and pathology databases and analyzed the expression of HTR mRNAs and their 5-HT receptor protein products across 

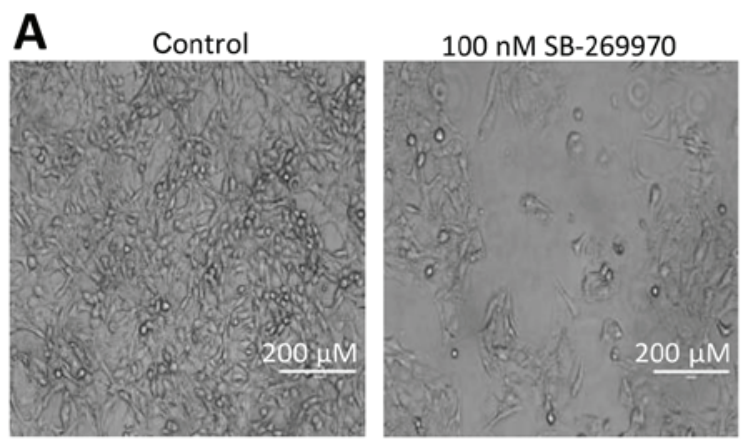

B
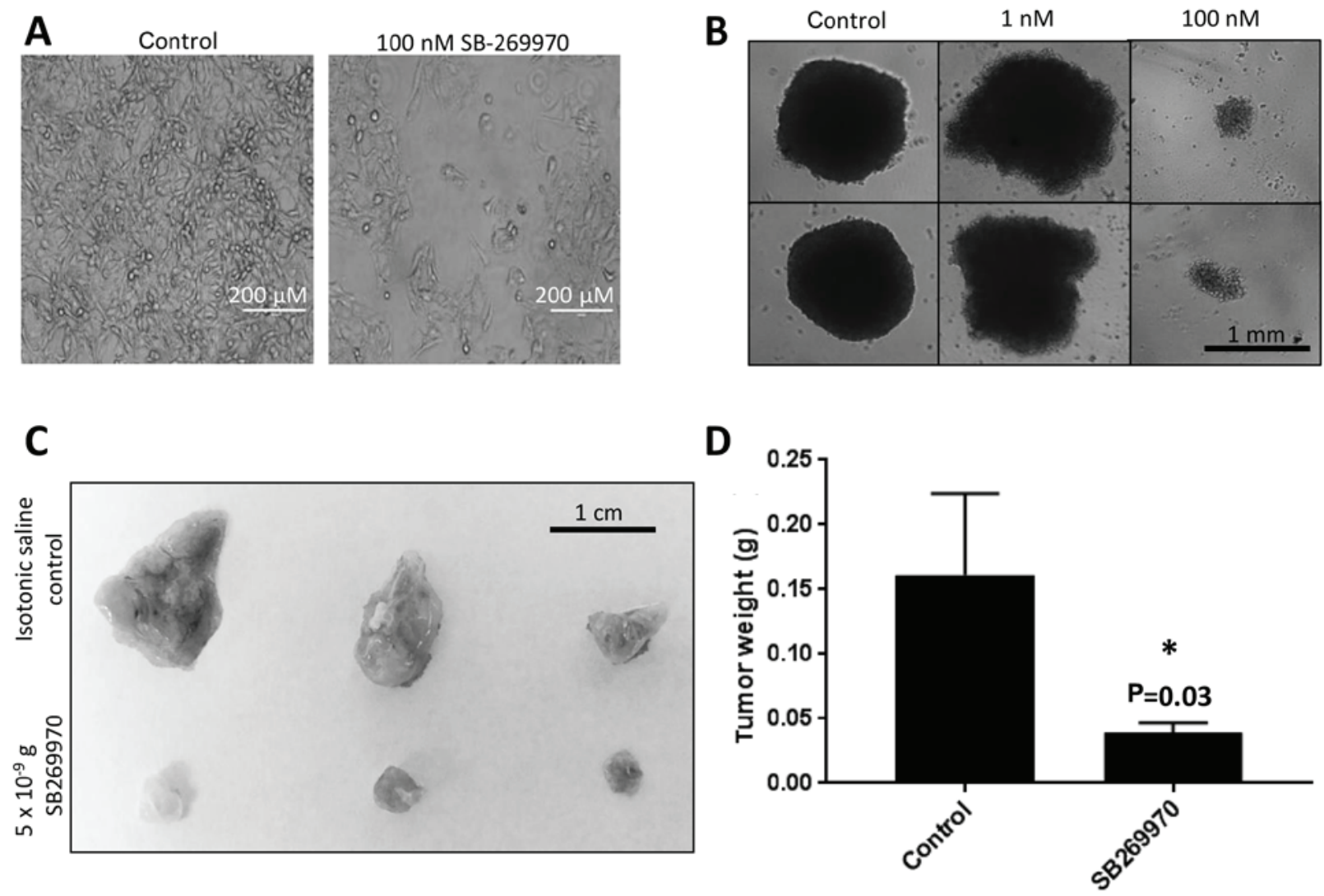

Figure 4. 5-HT7 antagonism inhibits cell viability in multiple tumor models. (A) SW872 liposarcoma cells were treated for 48 h with 100 nM SB-269970 (5-HT7 inhibitor) or a sham control, and images were collected of the cultures. (B) Tumor spheroids were generated using HOS osteosarcoma cell lines and treated with 1 or $100 \mathrm{nM}$ SB-269970 (5-HT7 inhibitor) or a sham control. Images of the spheroids were collected after 48 h. (C and D) CAM CosB hemangiosarcoma tumors were treated with 100 nM SB-269970 (5-HT7 inhibitor) or a sham control for 72 h, after which the tumors were harvested, weighed, and photographed. ${ }^{\mathrm{P}}<0.05$ vs. control.

a large panel of cell lines and tissues representing the most common cancers in humans. We observed clear gene expression clustering of multiple HTR mRNAs based on cancer cell line origin and that many of the 5-HT receptors were present in the majority of the cancer types examined. While the Human Protein Atlas database did not house enough matching normal controls for statistical analysis of over/underexpression of the 5-HT receptors in cancer, future studies should take advantages of tumor tissue array technologies to comprehensively evaluate this possibility in order to identify specific tumor types that may show benefit from blocking serotonin signaling.

A handful of molecular studies have attempted to identify downstream signaling mediators of the 5-HT receptors that contribute to serotonin-induced tumor growth. One study identified gut-derived serotonin stimulation of RUNX2, a transcription factor involved in bone and cartilage development and maintenance, as a facilitator for breast cancer metastasis to the bone (19). Moreover, serotonin has been shown to promote the activation of $\beta$ catenin $(7,17)$, a protein known to induce tumor cell growth, migration, and pluripotency (36). A meta-analysis of the Metabric dataset, which characterized the genomic landscape of 2000 breast cancer patients, identified active serotonin metabolism as a major metabolic feature of the poor prognosis cluster of patients (37), and serotonin has been shown to contribute to pancreatic tumor growth promotion via its regulation of the Warburg effect in cells under metabolic stress (9). Serotonin may exert its effect not only on the tumor cells, but also on the tumor stroma as this neurotransmitter enhances tumor growth via modulation of the angiogenic properties of tumor endothelial cells $(12,38,39)$. In the current study, we did not observe serotonin-mediated increases in tumor cell proliferation for a panel of breast cancer, soft tissue sarcoma, and bone sarcoma cells, however the addition of this neurotransmitter did indeed enhance the activating phosphorylation of key mitogenic regulators in cancer cells.

Through the use of pharmacological inhibitors that selectively and specifically block individual 5-HT receptors, roles for several of the 5-HT receptors have been implicated in cancer cell proliferation. For instance, 5-HT1 receptors are essential for proliferation of bladder cancer, colorectal cancer, leiomyosarcoma, and small cell lung carcinoma $(15,32,40)$; 5-HT2 receptors for breast and prostate cancer proliferation $(25,34) ; 5$-HT3 receptors for breast and colorectal cancer proliferation $(34,41) ; 5$-HT4 receptors for prostate cancer proliferation (25); and 5-HT7 receptors for hepatocellular carcinoma proliferation (7). Despite the number of studies that examined only one or two of the 5-HT receptors, no report, to our knowledge, has described the efficacy of comprehensively blocking each 5-HT receptor across a panel of cancer cell lines. The current study individually blocked the activation of each known 5-HT receptor using highly selective pharmacological antagonists, revealing dose dependent decreases in tumor cell viability across most cell lines when treating with inhibitors of 5-HT1, 4, 5, 6 and 7. 

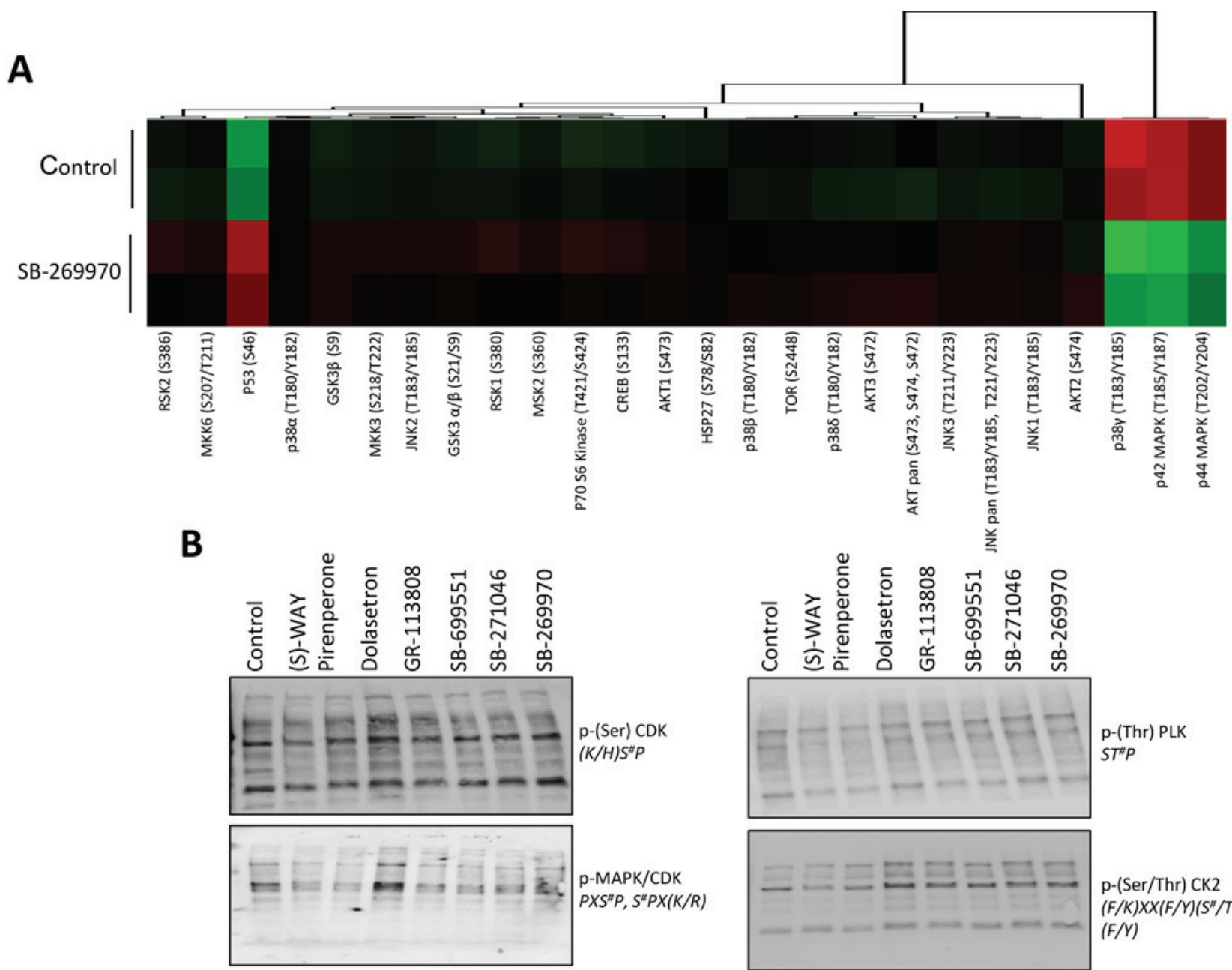

p-(Ser/Thr) CK2 $(F / K) X X(F / Y)\left(S^{\#} / T^{\#}\right)$

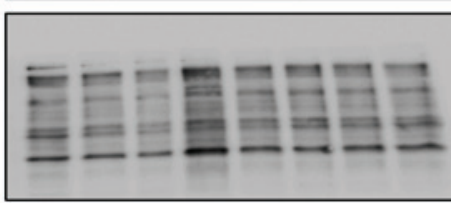

\section{p-AKT} $R X X\left(S^{u} T^{*}\right)$

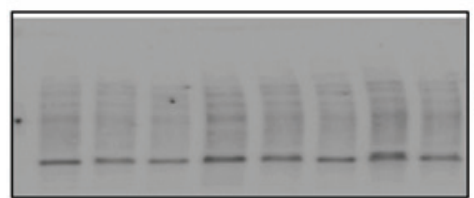
$(F / Y)$

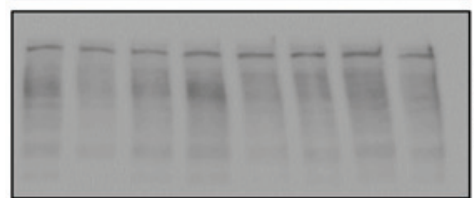

p-(Ser/Thr) AMPK $(L / M) X R X X\left(S^{\prime \prime} / T^{\prime \prime}\right)$ $R X X\left(S^{*} / T^{*}\right)$

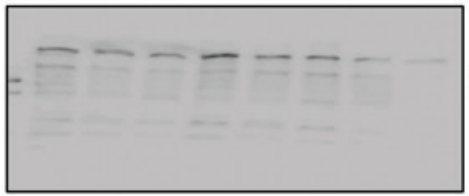

p-Thr-Pro-Glu $T^{*} P E, T^{*} P$
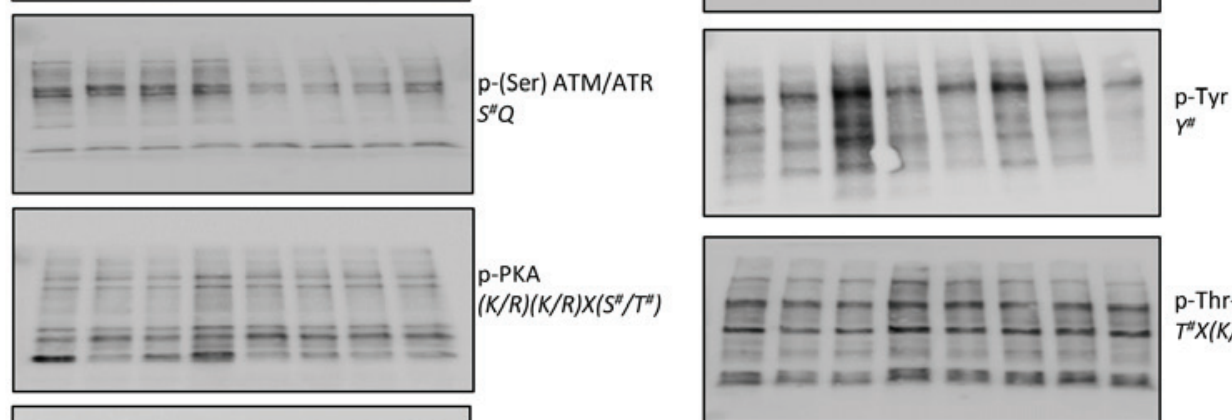

p-Thr-X-Arg

$T^{\#} X(K / R)$
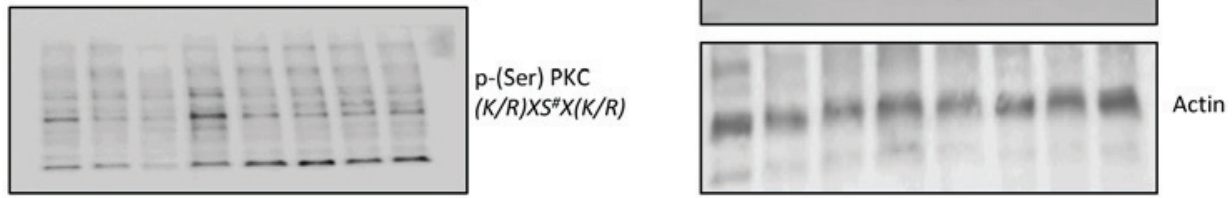

Figure 5. 5-HT7 antagonism disrupts oncogenic signaling in sarcoma cells. (A) Antibody array of HOS osteosarcoma cell lysates collected after treatment for $3 \mathrm{~h}$ with $100 \mathrm{nM}$ SB-269970 or a sham control. Red, enhanced expression; green, reduced expression. Two technical replicates of each time point are displayed. (B) HOS cells were treated with $100 \mathrm{nM} \mathrm{SB}-269970$ for $3 \mathrm{~h}$ or a sham control. Lysates were collected and subjected to immunoblot using the the KinomeView Profiling kit (Cell Signaling; a set of phospho-motif antibodies that cover a large portion of the kinome and react broadly with serine, threonine, and tyrosine phosphorylation sites mediated by known kinase families. "In the phospho-motif antibody description indicates a phosphorylated amino acid in the consensus motif. 
Table V. Association between SSRI usage and clinicopathological characteristics in breast cancer patients.

\begin{tabular}{|c|c|c|c|c|}
\hline Characteristics & $\begin{array}{c}\text { No SSRIs } \\
\mathrm{n}=391(93.3 \%)\end{array}$ & $\begin{array}{c}\text { SSRIs } \\
\mathrm{n}=28(6.7 \%)\end{array}$ & P-value & Significant \\
\hline \multicolumn{5}{|l|}{ Tumor stage } \\
\hline Stage I/II & 281 & 20 & 0.98 & No \\
\hline Stage III/IV & 110 & 8 & & \\
\hline \multicolumn{5}{|l|}{ Hormonal status } \\
\hline \multicolumn{5}{|l|}{ ER (no. of patients) } \\
\hline- & 101 & 11 & 0.58 & No \\
\hline+ & 274 & 17 & & \\
\hline \multicolumn{5}{|l|}{ PR (no. of patients) } \\
\hline- & 144 & 11 & 0.93 & No \\
\hline+ & 231 & 16 & & \\
\hline \multicolumn{5}{|l|}{ HER2 (no. of patients) } \\
\hline- & 100 & 8 & 0.80 & No \\
\hline+ & 257 & 19 & & \\
\hline \multicolumn{5}{|l|}{ Ki-67 index } \\
\hline Stage I/II mean (SEM) & $33.32(1.61)$ & $27.10(5.46)$ & 0.29 & No \\
\hline Stage III/IV mean (SEM) & $42.37(2.66)$ & $62.14(6.97)$ & 0.03 & Yes \\
\hline
\end{tabular}

The viability of some cell lines, such as the SK-BR-3 breast cancer cell line, were not greatly affected by the antagonists, suggesting cell-type dependence on some 5-HT receptors, but not on others. Selective inhibition of the 5-HT7 receptor resulted in increased levels of activated p53 and decreased levels of active MAPKs, as well as reduced tumor size following treatment of a CAM angiosarcoma tumor model. Based on kinome-level profiling, the majority of 5-HT receptor antagonists reduced the activation of downstream signaling proteins involved in proliferation and survival. In contrast, inhibition of 5-HT3 (which had no effect on tumor cell viability in our assays) exhibited opposite results, resulting in increased activation of signaling proteins involved in proliferation and survival. 5-HT3 is markedly distinct both structurally and functionally from the other 5-HT receptors. For instance, while all other 5-HT receptors are G-protein coupled receptors, 5-HT3 is a ligand gated ion channel that is permeable to sodium, potassium, and calcium ions (42).

Given that several selective 5-HT receptor antagonists (Ketanserin, Clozapine, Agomelatine and Buspirone) are clinically used for conditions including hypertension, anxiety, depression, and psychosis, and this class of drugs is one of the most widely prescribed therapeutics, it seems logical that retrospective and/or prospective analysis could easily determine if a correlation exists between use of these SSRIs and cancer risk/prognosis; however retrospective clinical analysis of patient data attempting to correlate cancer survival or time to progression with SSRI usage have led to mixed results. For instance, $33 \%$ (20/61) of studies have found a positive correlation between antidepressant use and breast or ovarian cancer (43), however many of these studies were supported financially by pharmaceutical sponsors and freedom from bias could not be confirmed. On closer examination, industry-backed studies were significantly less likely than those funded by non-industry financial streams to report a correlation between antidepressants and cancer risk $(0 \%$ [0/15] for industry-back studies; $43.5 \%$ [20/46] for non-industry backed studies) (43). Similarly conflicting results have been reported outside of breast or ovarian cancer, with no SSRI-mediated decreases in patient survival or time to disease progression observed for oral cancer (44), gastric cancer (45), cervical cancer (46), colorectal cancer (47), glioblastoma (48), or hepatocellular carcinoma (49). In contrast, SSRI use has been correlated with an enhanced risk of lung, colorectal, and prostate cancer (50-53), and increased mortality rates and tumor metastasis in melanoma $(10,54)$. Our findings from this report support the notion that SSRI use may contribute to enhanced tumor growth, given that we observed SSRIs were associated with a significantly increased breast tumor proliferative index in late stage cancer patients. Future studies should attempt to prospectively correlate SSRI use with accompanying changes in tumor proliferation and intracellular signaling pathways.

Interestingly, our data revealed that SSRI-use did not influence tumor proliferation rates in early stage breast tumors. Collectively, these many conflicting studies indicate that while serotonin signaling and use of SSRIs may contribute to some degree toward cancer progression, future studies are necessary to elucidate these conundrums. We demonstrated that the mRNA expression of neither HTR nor TPH genes were significantly different between normal breast tissue 


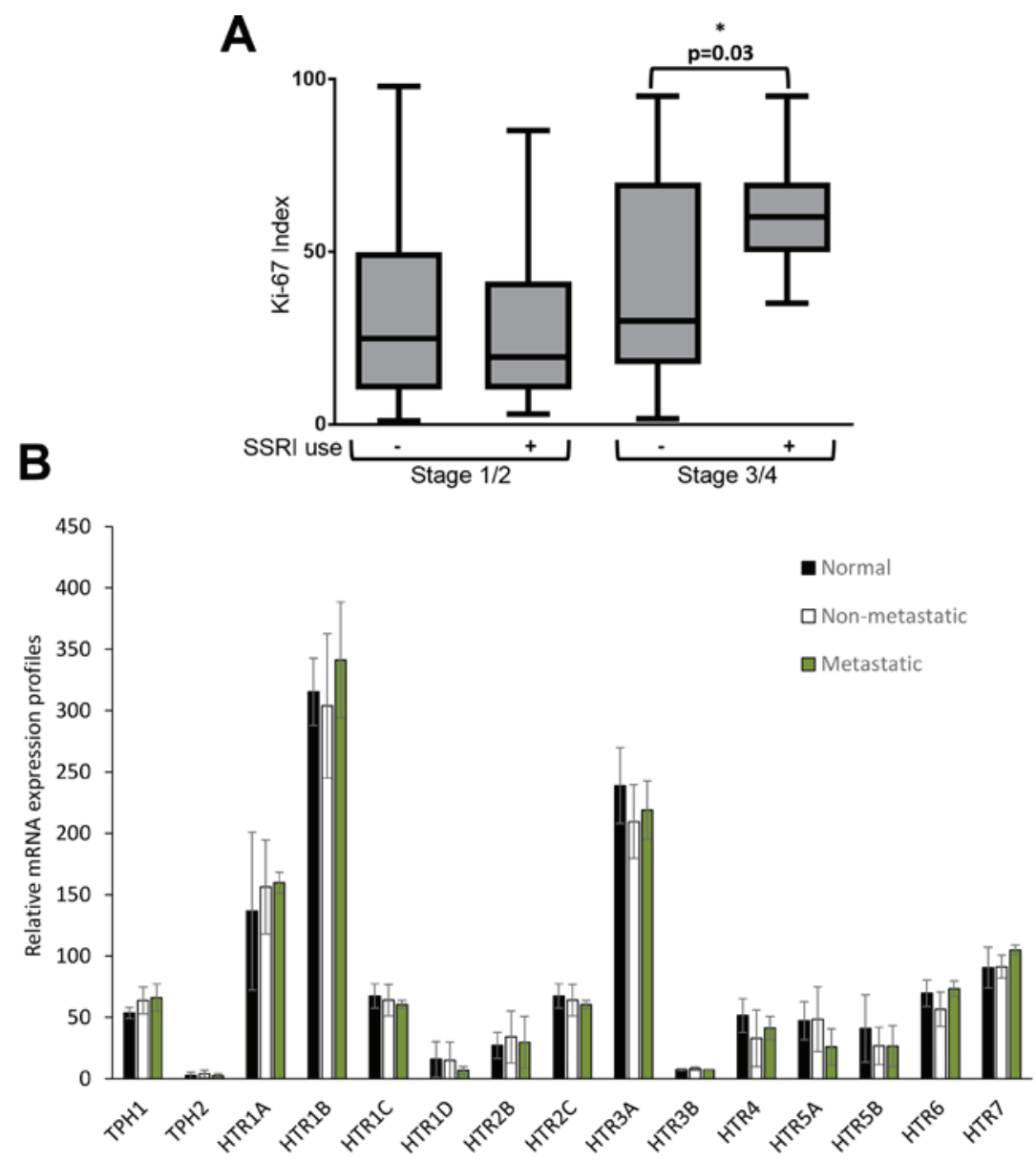

Figure 6. Retrospective analysis of selective serotonin reuptake inhibitor (SSRI) use in breast cancer patients. (A) A retrospective clinical analysis of 419 patients diagnosed with breast cancer was performed to assess the association between the use of SSRIs and breast tumor proliferation rates. Patients were stratified based on SSRI use, and the Ki-67-based proliferative index was determined from pathology samples taken at each patient's diagnostic biopsy. The data is displayed as box and whiskers plot illustrating the correlation between SSRI use and breast tumor proliferative rate as determined by the Ki-67 index. (B) Meta-analysis of $H T R$ and $T P H$ genes in normal mouse breast tissue, non-metastatic breast tumors from 67NR xenografts, and metastatic breast tumors from 4T1 xenografts was performed on Affymetrix mouse Genome 4302.0 Array data housed in Gene Expression Omnibus (GEO no. GSE62817).

and non-metastatic or metastatic xenograft breast tumor models. Unaccounted and uncontrolled factors that may contribute to the use of SSRIs could confound the outcome of these studies. Such factors could include lifestyle (e.g., diet), use of prescription and/or non-prescription drugs, and comorbidities (e.g., diabetes or heart disease)-all of which potentially could lead to increased SSRI use, and all of which could be attributed to a later stage of cancer at diagnosis and worse patient prognosis completely independent of SSRI use. Along these lines, a growing amount of literature has shown that stress in general, and specifically sympathetic nervous system responses through epinephrine and/or norepinephrine regulation of the $\beta$ adrenergic receptor pathways have been implicated in cancer progression $(29,55-57)$. Indeed, targeting the $\beta$ adrenergic stress response pathways has shown clinical efficacy against benign vascular tumors $(58,59)$ as well as rare, lethal sarcomas (60-63). It is very possible that greater psychological stress in late stage patients, which impacts a number of physiological pathways and would be factor leading to higher SSRI use, is a confounding contributor to increased cancer risk and poor clinical outcomes associated with antidepressant use.

Our findings suggest that serotonin influences tumor cell viability and behavior at the cellular level. Whether this translates to clinical outcomes needs to be confirmed in future randomized trials given the mixed results reported from a large number of retrospective studies and the likely confounders associated with lifestyle, drug use, comorbidities, or overall stress levels. The data presented here and those from other laboratories suggest an underlying psychophysiological regulation of tumor cells, yet how these characteristics manifest at the clinical level is yet to be definitively determined. Pending further studies, the likely association between SSRIs and worsening cancer outcome should be a reason to pause, especially in view of availability of other lines of medications for depression and anxiety that do not depend on similar serotonin-dependent pathways.

\section{Acknowledgements}

Not applicable.

\section{Funding}

The present study was supported by grants to BAB from the Sarcoma Foundation of America, Angiosarcoma Awareness Foundation to EBD from the Sarcoma Foundation of America, 
and to $\mathrm{ZN}$ from the Cancer Prevention and Research Institute of Texas (CPRIT RP120528).

\section{Availability of data and materials}

The datasets generated and/or analyzed during the current study are available in the Cancer Cell Line Encyclopedia (CCLE; www.broadinstitute.org/ccle/home), Human Protein Atlas repository (www.proteinatlas.org) and Gene Expression Omnibus (GEO) repository (https:/www.ncbi.nlm.nih.gov/ geo/; GEO no. GSE62817). All other data are included in this published article.

\section{Authors' contributions}

YB, AR, AB, LP, CAN, SL and TK acquired and interpreted the data. ERD, ZN conceived and designed the study and critically revised the manuscript. BAB conceived and designed the study and drafted the manuscript.

\section{Ethics approval and consent to participate}

Retrospective analysis of clinical data was performed with the approval of the Texas Tech University Health Sciences Center Institutional Review Board. All animal experiments used embryonated eggs prior to day 16, therefore these experiments were considered exempt from approval by the Texas Tech University Health Sciences Center Institutional Animal Care and Use Committee regulations for the care and use of animals in experimental procedures.

\section{Patient consent for publication}

Not applicable.

\section{Competing of interests}

The authors declare no conflict of interest.

\section{References}

1. Sanjida S, Janda M, Kissane D, Shaw J, Pearson SA, DiSipio T and Couper J: A systematic review and meta-analysis of prescribing practices of antidepressants in cancer patients. Psychooncology 25: 1002-1016, 2016.

2. Collet C, Schiltz C, Geoffroy V, Maroteaux L, Launay JM and de Vernejoul MC: The serotonin 5-HT2B receptor controls bone mass via osteoblast recruitment and proliferation. FASEB J 22: 418-427, 2008.

3. Fanburg BL and Lee SL: A new role for an old molecule: Serotonin as a mitogen. Am J Physiol 272: L795-L806, 1997.

4. Lesurtel M, Graf R, Aleil B, Walther DJ, Tian Y, Jochum W, Gachet C, Bader M and Clavien PA: Platelet-derived serotonin mediates liver regeneration. Science 312: 104-107, 2006.

5. Raymond JR, Mukhin YV, Gelasco A, Turner J, Collinsworth G, Gettys TW, Grewal JS and Garnovskaya MN: Multiplicity of mechanisms of serotonin receptor signal transduction. Pharmacol Ther 92: 179-212, 2001.

6. Christensen DK, Armaiz-Pena GN, Ramirez E, Matsuo K, Zimmerman B, Zand B, Shinn E, Goodheart MJ, Bender D, Thaker PH, et al: SSRI use and clinical outcomes in epithelial ovarian cancer. Oncotarget 7: 33179-33191, 2016

7. Fatima S, Shi X, Lin Z, Chen GQ, Pan XH, Wu JC, Ho JW, Lee NP, Gao H, Zhang G, et al: 5-Hydroxytryptamine promotes hepatocellular carcinoma proliferation by influencing $\beta$-catenin. Mol Oncol 10: 195-212, 2016.
8. Gautam J, Bae YK and Kim JA: Up-regulation of cathepsin S expression by HSP90 and 5-HT7 receptor-dependent serotonin signaling correlates with triple negativity of human breast cancer. Breast Cancer Res 161: 29-40, 2017.

9. Jiang SH, Li J, Dong FY, Yang JY, Liu DJ, Yang XM, Wang YH, Yang MW, Fu XL, Zhang XX, et al: Increased serotonin signaling contributes to the warburg effect in pancreatic tumor cells under metabolic stress and promotes growth of pancreatic tumors in mice. Gastroenterology 153: 277-291, 2017.

10. Kubera M, Grygier B, Wrona D, RogóżZ, Roman A, Basta-Kaim A, Budziszewska B, Leskiewicz M, Jantas D, Nowak W, et al: Stimulatory effect of antidepressant drug pretreatment on progression of B16F10 melanoma in high-active male and female C57BL/6J mice. J Neuroimmunol 240-241: 34-44, 2011.

11. Liang C, Chen W, Zhi X, Ma T, Xia X, Liu H, Zhang Q, Hu Q, Zhang Y, Bai X and Liang T: Serotonin promotes the proliferation of serum-deprived hepatocellular carcinoma cells via upregulation of FOXO3a. Mol Cancer 12: 14, 2013.

12. Peters MA, Walenkamp AM, Kema IP, Meijer C, de Vries EG and Oosting SF: Dopamine and serotonin regulate tumor behavior by affecting angiogenesis. Drug Resist Updat 17: 96-104, 2014.

13. Sarrouilhe D, Clarhaut J, Defamie N and Mesnil M: Serotonin and cancer: What is the link? Curr Mol Med 15: 62-77, 2015.

14. Siddiqui EJ, Shabbir M, Mikhailidis DP, Thompson CS and Mumtaz FH: The role of serotonin (5-hydroxytryptamine1A and $1 \mathrm{~B})$ receptors in prostate cancer cell proliferation. J Urol 176: 1648-1653, 2006.

15. Siddiqui EJ, Shabbir MA, Mikhailidis DP, Mumtaz FH and Thompson CS: The effect of serotonin and serotonin antagonists on bladder cancer cell proliferation. BJU Int 97: 634-639, 2006.

16. Siddiqui EJ, Thompson CS, Mikhailidis DP and Mumtaz FH: The role of serotonin in tumour growth (review). Oncol Rep 14: 1593-1597, 2005

17. Sui H, Xu H, Ji Q, Liu X, Zhou L, Song H, Zhou X, Xu Y, Chen Z, Cai J, et al: 5-hydroxytryptamine receptor (5-HT1DR) promotes colorectal cancer metastasis by regulating Axin $1 / \beta$-catenin/MMP-7 signaling pathway. Oncotarget 6 : 25975-25987, 2015.

18. Vicaut E, Laemmel E and Stucker O: Impact of serotonin on tumour growth. Ann Med 32: 187-194, 2000.

19. Zong JC, Wang X, Zhou X, Wang C, Chen L, Yin LJ, He BC and Deng ZL: Gut-derived serotonin induced by depression promotes breastcancerbonemetastasisthrough the RUNX2/PTHrP/RANKL pathway in mice. Oncol Rep 35: 739-748, 2016.

20. Julius D, Huang KN, Livelli TJ, Axel R and Jessell TM: The $5 \mathrm{HT} 2$ receptor defines a family of structurally distinct but functionally conserved serotonin receptors. Proc Natl Acad Sci USA 87: 928-932, 1990.

21. Julius D, Livelli TJ, Jessell TM and Axel R: Ectopic expression of the serotonin $1 \mathrm{c}$ receptor and the triggering of malignant transformation. Science 244: 1057-1062, 1989.

22. Jungwirth N, Haeberle L, Schrott KM, Wullich B and Krause FS: Serotonin used as prognostic marker of urological tumors. World J Urol 26: 499-504, 2008.

23. Dizeyi N, Bjartell A, Nilsson E, Hansson J, Gadaleanu V, Cross N and Abrahamsson PA: Expression of serotonin receptors and role of serotonin in human prostate cancer tissue and cell lines. Prostate 59: 328-336, 2004

24. Launay JM, Birraux G, Bondoux D, Callebert J, Choi DS, Loric $S$ and Maroteaux L: Ras involvement in signal transduction by the serotonin 5-HT2B receptor. J Biol Chem 271: 3141-3147, 1996.

25. Dizeyi N, Bjartell A, Hedlund P, Tasken KA, Gadaleanu V and Abrahamsson PA: Expression of serotonin receptors $2 B$ and 4 in human prostate cancer tissue and effects of their antagonists on prostate cancer cell lines. Eur Urol 47: 895-900, 2005.

26. Dizeyi N, Hedlund P, Bjartell A, Tinzl M, Austild-Tasken K and Abrahamsson PA: Serotonin activates MAP kinase and PI3K/Akt signaling pathways in prostate cancer cell lines. Urol Oncol 29: 436-445, 2011.

27. Barretina J, Caponigro G, Stransky N, Venkatesan K, Margolin AA, Kim S, Wilson CJ, Lehár J, Kryukov GV, Sonkin D, et al: The cancer cell line encyclopedia enables predictive modelling of anticancer drug sensitivity. Nature 483: 603-607, 2012.

28. Modiano JF: Comparative pathogenesis of cancers in animals and humans. Vet Sci 3: 2016.

29. Stiles JM, Amaya C, Rains S, Diaz D, Pham R, Battiste J, Modiano JF, Kokta V, Boucheron LE, Mitchell DC and Bryan BA: Targeting of beta adrenergic receptors results in therapeutic efficacy against models of hemangioendothelioma and angiosarcoma. PLoS One 8: e60021, 2013. 
30. Spencer C, Montalvo J, McLaughlin SR and Bryan BA: Small molecule inhibition of cytoskeletal dynamics in melanoma tumors results in altered transcriptional expression patterns of key genes involved in tumor initiation and progression. Cancer Genomics Proteomics 8: 77-85, 2011.

31. Gautam J, Banskota S, Regmi SC, Ahn S, Jeon YH, Jeong H, Kim SJ, Nam TG, Jeong BS and Kim JA: Tryptophan hydroxylase 1 and 5-HT7 receptor preferentially expressed in triple-negative breast cancer promote cancer progression through autocrine serotonin signaling. Mol Cancer 15: 75, 2016.

32. Gurbuz N, Asoglu MR, Ashour AA, Salama S, Kilic GS and Ozpolat B: A selective serotonin 5-HT1B receptor inhibition suppresses cells proliferation and induces apoptosis in human uterine leiomyoma cells. Eur J Obstet Gynecol Reprod Biol 206: $114-119,2016$.

33. Gwynne WD, Hallett RM, Girgis-Gabardo A, Bojovic B, Dvorkin-Gheva A, Aarts C, Dias K, Bane A and Hassell JA: Serotonergic system antagonists target breast tumor initiating cells and synergize with chemotherapy to shrink human breast tumor xenografts. Oncotarget 8: 32101-32116, 2017.

34. Hejazi SH, Ahangari G and Deezagi A: Alternative Viewpoint Against Breast Cancer Based on Selective Serotonin Receptors 5HTR3A and 5HTR2A Antagonists that can Mediate Apoptosis in MCF-7 Cell Line. Curr Drug Discov Technol 12: 240-249, 2015.

35. Abdel-Hamid NM, Shehata DE, Abdel-Ghany AA, Ragaa A and Wahid A: Serum serotonin as unexpected potential marker for staging of experimental hepatocellular carcinoma. Biomed Pharmacother 83: 407-411, 2016

36. Kourtidis A, Lu R, Pence LJ and Anastasiadis PZ: A central role for cadherin signaling in cancer. Exp Cell Res 358: 78-85, 2017.

37. Leoncikas V, Wu H, Ward LT, Kierzek AM and Plant NJ Generation of 2,000 breast cancer metabolic landscapes reveals a poor prognosis group with active serotonin production. Sci Rep 6: 19771, 2016.

38. Asada M, Ebihara S, Yamanda S, Niu K, Okazaki T, Sora I and Arai H: Depletion of serotonin and selective inhibition of $2 B$ receptor suppressed tumor angiogenesis by inhibiting endothelial nitric oxide synthase and extracellular signal-regulated kinase 1/2 phosphorylation. Neoplasia 11: 408-417, 2009.

39. Banskota S, Gautam J, Regmi SC, Gurung P, Park MH, Kim SJ, Nam TG, Jeong BS and Kim JA: BJ-1108, a 6-amino-2,4,5-trimethylpyridin-3-ol analog, inhibits serotonin-induced angiogenesis and tumor growth through PI3K/NOX pathway. PLoS One 11: e0148133, 2016.

40. Cattaneo MG, Palazzi E, Bondiolotti G and Vicentini LM: 5-HT1D receptor type is involved in stimulation of cell proliferation by serotonin in human small cell lung carcinoma. Eur J Pharmacol 268: 425-430, 1994.

41. Ataee R, Ajdary S, Zarrindast M, Rezayat M, Shokrgozar MA and Ataee A: Y25130 hydrochloride, a selective 5HT3 receptor antagonist has potent antimitogenic and apoptotic effect on HT29 colorectal cancer cell line. Eur J Cancer Prev 19: 138-143, 2010.

42. Engel M, Smidt MP and van Hooft JA: The serotonin 5-HT3 receptor: A novel neurodevelopmental target. Front Cell Neurosci 7: 76, 2013.

43. Cosgrove L, Shi L, Creasey DE, Anaya-McKivergan M, Myers JA and Huybrechts KF: Antidepressants and breast and ovarian cancer risk: A review of the literature and researchers' financial associations with industry. PLoS One 6: e18210, 2011.

44. Chung CM, Kuo TM, Chiang SL, Wang ZH, Hung CC, Lane HY, Liu CS and Ko YC: Antidepressants in association with reducing risk of oral cancer occurrence: A nationwide population-based cohort and nested case-control studies. Oncotarget 7: $11687-11695,2016$

45. Hsieh YH, Chiu WC, Lin CF, Chan HL, Liang HY, Lee Y, McIntyre RS and Chen VC: Antidepressants and gastric cancer: A nationwide population-based nested case-control study. PLoS One 10: e0143668, 2015.

46. Chan HL, Hsieh YH, Lin CF, Liang HY, Huang KY, Chiu WC, Lee Y, McIntyre RS and Chen VC: Invasive cervical cance and antidepressants: A nationwide population-based study. Medicine 94: e1866, 2015.

47. Lee HC, Chiu WC, Wang TN, Liao YT, Chien IC, Lee Y, McIntyre RS, Chen PC and Chen VC: Antidepressants and colorectal cancer: A population-based nested case-control study. J Affect Disord 207: 353-358, 2017
48. Caudill JS, Brown PD, Cerhan JH and Rummans TA: Selective serotonin reuptake inhibitors, glioblastoma multiforme and impact on toxicities and overall survival: The mayo clinic experience. Am J Clin Oncol 34: 385-387, 2011.

49. Pocha C, Knott A, Rector TS and Dieperink E: Are selective serotonin reuptake inhibitors associated with hepatocellular carcinoma in patients with hepatitis C? J Clin Psychiatry 75: e1122-e1126, 2014.

50. Boursi B, Lurie I, Haynes K, Mamtani R and Yang YX: Chronic therapy with selective serotonin reuptake inhibitors and survival in newly diagnosed cancer patients. Eur J Cancer Care(Engl) 27 e12666, 2018.

51. Boursi B, Lurie I, Mamtani R, Haynes K and Yang YX Anti-depressant therapy and cancer risk: A nested case-control study. Eur Neuropsychopharmacol 25: 1147-1157, 2015.

52. Haukka J, Sankila R, Klaukka T, Lonnqvist J, Niskanen L, Tanskanen A, Wahlbeck K and Tiihonen J: Incidence of cancer and antidepressant medication: Record linkage study. Int J Cancer 126: 285-296, 2010.

53. Xu W, Tamim H, Shapiro S, Stang MR and Collet JP: Use of antidepressants and risk of colorectal cancer: A nested case-control study. Lancet Oncol 7: 301-308, 2006.

54. Brandes LJ, Arron RJ, Bogdanovic RP, Tong J, Zaborniak CL, Hogg GR, Warrington RC, Fang W and LaBella FS: Stimulation of malignant growth in rodents by antidepressant drugs at clinically relevant doses. Cancer Res 52: 3796-3800, 1992.

55. Montoya A, Amaya CN, Belmont A, Diab N, Trevino R, Villanueva G, Rains S, Sanchez LA, Badri N, Otoukesh S, et al: Use of non-selective $\beta$-blockers is associated with decreased tumor proliferative indices in early stage breast cancer. Oncotarget 8: 6446-6460, 2017.

56. Thaker PH, Han LY, Kamat AA, Arevalo JM, Takahashi R, Lu C, Jennings NB, Armaiz-Pena G, Bankson JA, Ravoori M, et al: Chronic stress promotes tumor growth and angiogenesis in a mouse model of ovarian carcinoma. Nat Med 12: 939-944, 2006.

57. Watkins JL, Thaker PH, Nick AM, Ramondetta LM, Kumar S, Urbauer DL, Matsuo K, Squires KC, Coleman RL, Lutgendorf SK, et al: Clinical impact of selective and nonselective beta-blockers on survival in patients with ovarian cancer. Cancer 121: 3444-3451, 2015.

58. Leaute-Labreze C, Hoeger P, Mazereeuw-Hautier J, Guibaud L, Baselga E, Posiunas G, Phillips RJ, Caceres H, Lopez Gutierrez JC, Ballona R, et al: A randomized, controlled trial of oral propranolol in infantile hemangioma. N Engl J Med 372: 735-746, 2015

59. Leaute-Labreze C and Taieb A: Efficacy of beta-blockers in infantile capillary haemangiomas: The physiopathological significance and therapeutic consequences. Ann Dermatol Venereol 135: 860-862, 2008

60. Banavali S, Pasquier E and Andre N: Targeted therapy with propranolol and metronomic chemotherapy combination: Sustained complete response of a relapsing metastatic angiosarcoma. Ecancermedicalscience 9: 499, 2015.

61. Chow W, Amaya CN, Rains S, Chow M, Dickerson EB and Bryan BA: Growth attenuation of cutaneous angiosarcoma with propranolol-mediated $\beta$-blockade. JAMA Dermatol 151: 1226-1229, 2015.

62. Daguze J, Saint-Jean M, Peuvrel L, Cassagnau E, Quéreux G, Khammari A and Dréno B: Visceral metastatic angiosarcoma treated effectively with oral cyclophosphamide combined with propranolol. JAAD Case Rep 2: 497-499, 2016.

63. Pasquier E, Andre N, Street J, Chougule A, Rekhi B, Ghosh J, Philip DSJ, Meurer M, MacKenzie KL, Kavallaris M and Banavali SD: Effective management of advanced angiosarcoma by the synergistic combination of propranolol and vinblastine-based metronomic chemotherapy: A bench to bedside study. EBioMedicine 6: 87-95, 2016.

This work is licensed under a Creative Commons Attribution-NonCommercial-NoDerivatives 4.0 International (CC BY-NC-ND 4.0) License. 